\title{
Mg(II) Selective PVC Membrane Electrode Based on Methyl Phenyl Semicarbazone as an Ionophore
}

\author{
Sulekh Chandra, ${ }^{1}$ Kusum Sharma, ${ }^{2}$ and Adarsh Kumar ${ }^{1,2}$ \\ ${ }^{1}$ Department of Chemistry, Zakir Husain College, University of Delhi, J. L. Nehru Marg, New Delhi 110002, India \\ ${ }^{2}$ Department of Applied Chemistry, MAIT, GGSIP University, Sector 22, Rohini, New Delhi 110085, India
}

Correspondence should be addressed to Sulekh Chandra; schandra_00@yahoo.com

Received 27 June 2012; Revised 11 October 2012; Accepted 16 October 2012

Academic Editor: Tingyue Gu

Copyright (C) 2013 Sulekh Chandra et al. This is an open access article distributed under the Creative Commons Attribution License, which permits unrestricted use, distribution, and reproduction in any medium, provided the original work is properly cited.

A PVC-membrane-based $\mathrm{Mg}$ (II) selective electrode was constructed using methyl phenyl semicarbazone (MPS) as a neutral carrier. The sensor exhibits a Nernstian response for $\mathrm{Mg}$ (II) ion over a wide concentration range $1.0 \times 10^{-8}$ to $1.0 \times 10^{-1} \mathrm{M}$ with the slope of $28.4 \mathrm{mV} /$ per decade having detection limit $1.7 \times 10^{-9} \mathrm{M}$. It was relatively a fast response time $\left(<10 \mathrm{~s}\right.$ for concentration $\geq 1.0 \times 10^{-3}$ and $<15 \mathrm{~s}$ for concentration of $\geq 1.0 \times 10^{-6} \mathrm{M}$ ) and can be used for 8 months without any considerable divergence in potentials. The proposed sensor revealed relatively good selectivity and high sensitivity for $\mathrm{Mg}(\mathrm{II})$ over a mono-, di-, and trivalent cation and can be used in a pH range of 1.0-9.5. It was also successfully used as an indicator electrode in potentiometer titration and in the analysis of concentration of magnesium in various real samples.

\section{Introduction}

Analytical methods for determining the alkaline earth metal ion have been studied extensively due to their importance in biological process $[1,2]$. Polymeric membrane ion-selective electrode (ISE) provides one of the most powerful sensing methods because it is possible to select various sensory elements according to the charge and size of the target ion in clinical and environmental assays [3-10]. The ISEs dynamic response is generated by selective complexation of the target ion by ionophores dispersed in a polyvinyl chloride (PVC) matrix. The quick determination of minute quantities of ionic species by simple method has great importance in analytical chemistry. Potentiometric detection based on ionselective electrode (ISE) is the simplest method; it has an advantage such as simple design and operation, reasonable selectivity, fast response applicability to colored, and turbid solution. Schiff's base with $\mathrm{N}$ and $\mathrm{O}$ donor atoms is well known $[11,12]$ to form strong complexes with alkaline earth metal ion. Some of the Schiff bases were reported which forms strong complexes with a specific ion due to geometric factor. Schiff base complexes have attracted much attention in solvent extraction $[13,14]$ as ion exchanger [15] as catalyst
[16]. Magnesium is found in dairy products, fish meat, and seafood. Besides this an adult human normally has $20 \mathrm{mg}$ magnesium of which half is found in bones and the other half within cells. It has been observed that the activity of $\mathrm{Mg}^{2+}$ in blood serum decreases during liver transplantation due to accumulation of citrate and concomitant chelation of $\mathrm{Mg}^{2+}$. Low $\mathrm{Mg}^{2+}$ activities were also found for certain suffering of acute migraine and headaches and in patient with cardiac diseases. The availability of ISEs with sufficient selectivity for $\mathrm{Mg}^{2+}$ has recently initiated a number of clinical investigations [17, 18]. Zhang et al. [19] reported magnesium-selective electrodes based on ETH 5504 as well as bis and tris (malondiamides) derivatives [20]. A review by Maj-Zurawaska [21] presented the ion magnesium-selective electrodes and their applications in analytical chemistry. However, most of the developed electrodes suffer from narrow working concentration range and severe interference from calcium. O'Donnell et al. [22] developed electrodes using various octaethylene bis(malonic acid diamides) and tris(malonic acid diamides) in PVC with 2-nitrophenyl octyl ether as solvent mediator. Saleh [23] reported a PVC-based electrode using phenylenebis(ditolyl) phosphine oxide as ionophore. 
The electrode gives an excellent discrimination of $\mathrm{Ca}^{2+}$ in the concentration range $6 \times 10^{-5}$ to $1.0 \times 10^{-1} \mathrm{M}$.

Preliminary studies show that methyl phenyl semicarbazone (MPS) tends to show affinity for magnesium. Taking into consideration all the above facts that methyl phenyl semicarbazone (MPS) has been studied as an electroactive phase in PVC matrix for the fabrication of $\mathrm{Mg}^{2+}$-selective electrode, and the results are presented in this paper. The present electrode shows good selectivity for $\mathrm{Mg}^{2+}$ as compared to other cations.

\section{Experimental}

2.1. Chemicals. Reagent grade high molecular weight PVC, tetrahydrofuran (THF), acetophenone, semicarbazidehydrochloride, (Aldrich, Delhi) were used as received. Tris(2ethylehexyl) phosphate (TEP), dioctylphthalate (DOP), nbenzylacetate (NBA), Tri-n-butylphthalate (TNBP), nitrobenzene (NB), Dibutylphthalate (DBP), and sodium tetraphenyl borate (NaTPB) and nitrate of all metal used (Merck) were of highest purity available and used without any further purification. Throughout double distilled deionized water was used.

2.2. Physical Measurement. The $\mathrm{C}, \mathrm{H}$, and $\mathrm{N}$ were analyzed on a carlo-Erba 1106 elemental analysis. Electron impact mass spectra were recorded on JEOL, JMS, DX-303 mass spectrophotometer; ${ }^{1} \mathrm{H}$ NMR spectra were recorded on a Hitachi FT-NMR, Model R-600 spectrophotometer using $\mathrm{CDCl}_{3}$ as solvent. Chemical shift is given in ppm relative to tetra methylsilane. IR spectra (CsI) were recorded on a Bruker FT-IR spectrophotometer Model no. TEN 50R-27 spectrophotometer.

2.3. Synthesis of Ionophore. In (Figure 1) the hot ethanolic solutions $(20 \mathrm{~mL})$ of acetophenone $(1.12 \mathrm{~mL} 0.01 \mathrm{~m} \mathrm{~mol})$, semicarbazide hydrochloride $(1.12 \mathrm{~g} 0.01 \mathrm{~mol})$, and sodium acetate $(0.82 \mathrm{~g}, 0.01 \mathrm{~mol})$ were mixed with contant stirring [24]. On cooling a yellowish coloured compound has separated out. It was filtered, washed several times with cold $\mathrm{EtOH}$, and dried in vacuum over $\mathrm{P}_{4} \mathrm{O}_{10}$.

2.4. Methylphenylsemicarbazone. Yield (85.0\%), M.P: $165^{\circ} \mathrm{C}$, Anal calc. for $(\%)=\mathrm{C}_{9} \mathrm{H}_{11} \mathrm{~N}_{3} \mathrm{O}: \mathrm{C}, 61.02 ; \mathrm{H}, 6.21 \mathrm{~N}, 23.72$; Found: (\%) : 61.36; H, 6.25; N, 23.86; Mass. $(\mathrm{m} / \mathrm{z}): 176\left(\mathrm{M}^{-}\right)$ FT-IR(CsI): $v\left(\mathrm{NH}_{2}\right) 3479(\mathrm{~b}), v(\mathrm{NH}) 3148(\mathrm{~b}), v(\mathrm{C}=\mathrm{N}) 1584$, $v(\mathrm{C}=\mathrm{O}) 1742 ;{ }^{1} \mathrm{HNMR}\left(\mathrm{CDCl}_{3} 300 \mathrm{MHz}\right): \delta \mathrm{ppm}=3.36(2 \mathrm{H}$, $\left.\mathrm{s},-\mathrm{NH}_{2}\right) ; 6.48-7.79(\mathrm{Ar}-\mathrm{H}) ; 2.43-2.5\left(3 \mathrm{H}, \mathrm{CH}_{3}\right)$.

2.5. Potential Measurements. All the membrane electrode potential measurements were performed at constant temperature $\left(25 \pm 0.05^{\circ} \mathrm{C}\right)$ using digital $\mathrm{pH}$ meter, potentiometer (ELICO L1-10, India) in conjugation with saturated calomel electrodes as reference electrodes. The representation of electrochemical cell for the EMF measurements is as follows.

\section{External Reference Electrode (SCE) | Internal Solution $1.0 \times 10^{2} \mathrm{M} \mathrm{Mg}\left(\mathrm{NO}_{3}\right)_{2} \mid$ PVC Membrane | Test Solution | Internal (SCE) Reference Solution}

The membranes were prepared using the basic method given by Craggs et al. [25], with certain variations in composition of PVC, ionophore, and plasticizers/solvent mediators like DBP, NB, DOP, and TNBP. The PVC membrane solution was prepared by mixing of ionophore (5\%wt.), TNBP as plasticizer (60\%wt.), PVC (30\%wt.), and NaTBP (5\%wt.) dissolved in THF. The resulting mixture was poured into a petri dish. The THF was allowed to evaporate at room temperature. A flexible membrane with a thickness of $0.2-0.4 \mathrm{~mm}$ was obtained. The discs of $6 \mathrm{~mm}$ diameter were cut and pasted to a Pyrex glass-tube with the help of Araldite. After getting dried, this tube was filled with $1.0 \times 10^{-2} \mathrm{M}$ internal solution of magnesium and immersed in the $1.0 \times 10^{-2} \mathrm{M}$ magnesium nitrate solution, at least for 2-3 days prior to use. It is known [26] that the sensitivity, linearity, and selectivity obtained for a given ionophore depend significantly on the membrane composition and nature of the plasticizer used. Thus, the ratio of membrane ingredients, time of contact, and concentration of equilibrating solution were optimized after a good deal of experimentation. Membranes, which generate reproducibility and stable potentials, have been studied. The blank membrane having only PVC as membrane ingredients was also prepared and studied. While membrane having PVC with plasticizer generated small potential with slope of $5 \mathrm{mV} /$ decade.

\section{Results and Discussion}

4.1. Response of the Cations. The plasticized PVC-based membrane electrode containe (MPS) as the neutral ioncarrier generated stable potential responses in solutions containing magnesium. Therefore, we studied in detail the performance of the membrane electrodes based on this carrier (MPS) for magnesium(II) ion in aqueous solutions. In preliminary experiment, membranes with and without carriers were constructed. The membranes with no carrier displayed insignificant selectivity toward magnesium(II) ion, and its response was not reliable, whereas, in the presence of the proposed carrier, the optimized membranes demonstrated Nernstian response and remarkable selectivity for magnesium(II) ion over a wide variety of metal ions, including alkali $\left(\mathrm{Li}^{+}, \mathrm{Na}^{+}, \mathrm{K}^{+}, \mathrm{Cs}^{+}\right)$, alkaline-earth $\left(\mathrm{Ca}^{2+}\right.$, $\left.\mathrm{Ba}^{2+}\right)$, and transition and heavy metal ions $\left(\mathrm{Co}^{2+}, \mathrm{Ni}^{2+}\right.$, $\left.\mathrm{Ag}^{+}, \mathrm{Hg}^{2+}, \mathrm{Cd}^{2+}, \mathrm{Zn}^{2+}, \mathrm{Fe}^{3+}, \mathrm{Pb}^{2+}\right)$. Some of them gave zero potential. The potentiometric response curves obtained for individual ions with ionophore (MPS) under identical conditions are given in Figure 2. Among these ions, except for $\mathrm{Mg}(\mathrm{II})$ ion, for all other ions the slope of the corresponding potential versus $\log \left[\mathrm{Mn}^{+}\right]$plots is much lower than the expected Nernstian slopes of 59.0, $29.5 \mathrm{mV}$ per decade for the univalent and divalent cations, respectively, with very narrow linear ranges of concentration. This is likely due to the high selectivity of the ionophore for magnesium ions 


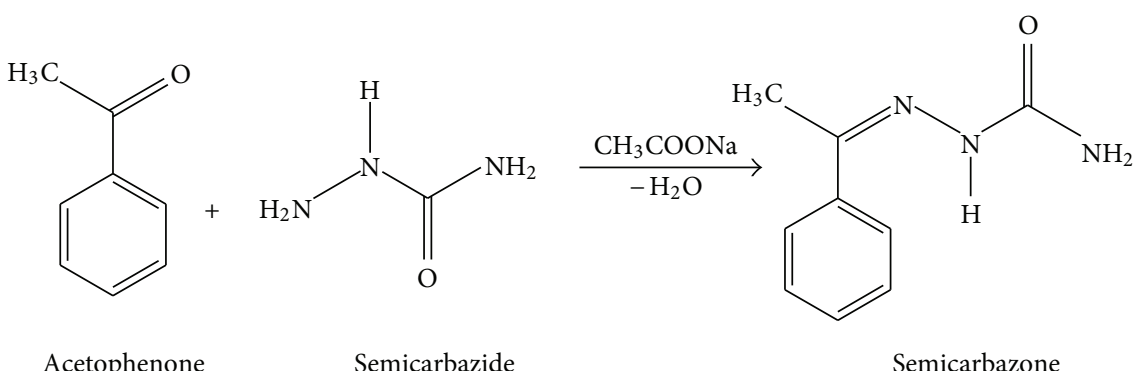

FIGURE 1: Syntheses of ionophore.

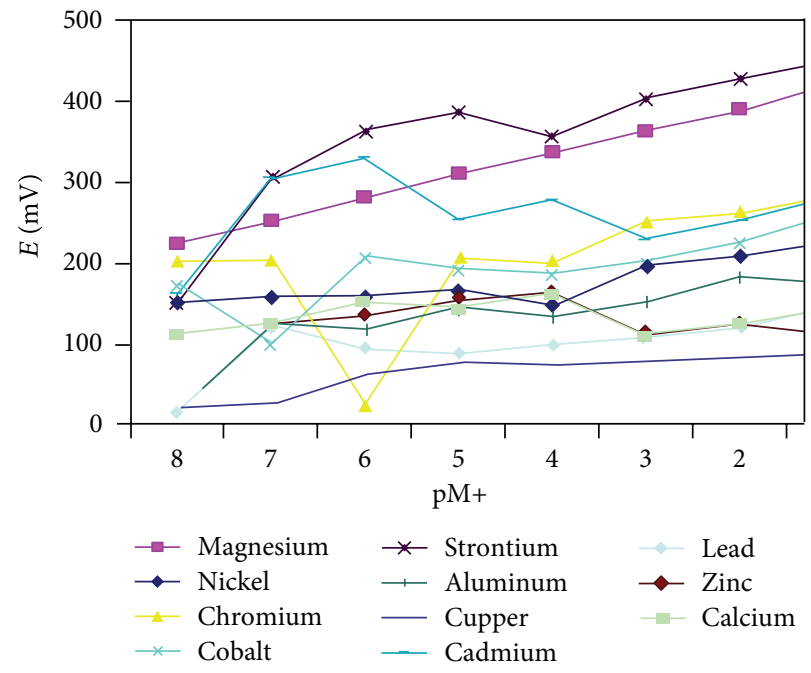

FIgURE 2: Potential response of various ion Selective electrodes based on MPS.

over other ions and rapid exchange kinetics of the resulting $\mathrm{Mg}(\mathrm{II})$-ionophore (MPS) complex. It has been observed that the membrane performs best with $\mathrm{Mg}^{2+}$ as the response is linear over a wide concentration $\left(1.0 \times 10^{-8}\right.$ to $\left.1.0 \times 10^{-1} \mathrm{M}\right)$. Thus, membranes are used as $\mathrm{Mg}^{2+}$ sensor.

4.2. Working Concentration Range and Slope of $\mathrm{Mg}^{2+}$ Sensor. Before starting any experimentation, the membranes were equilibrated with $1.0 \times 10^{-2} \mathrm{M} \mathrm{Mg}^{2+}$ solution. The experiments have shown that 2 days equilibration time is required for generating reproducible and stable potential. The working concentration range and slope have been evaluated from these plots and summarized in Table 1. It is seen from Figure 2 that the membrane without plasticizer (sensor no. 1) has composition ( $5: 30: 5$-MPS: PVC:NaTPB) (w/w\%); the concentration range is $1.0 \times 10^{-5}$ to $1.0 \times 10^{-1} \mathrm{M}$ with a slope of $35.5 \mathrm{mV} /$ decade of activity. Since the nature of plasticizer influences the dielectric constant of the membrane phase, the mobility of the ionophore molecular and state of compound [26], it were expected to play a key role in determining the ion-selective characteristics. So various plasticizers viz.DBP, NB, and TNBP were added in varying amounts to the membranes, and ion-selective characteristics

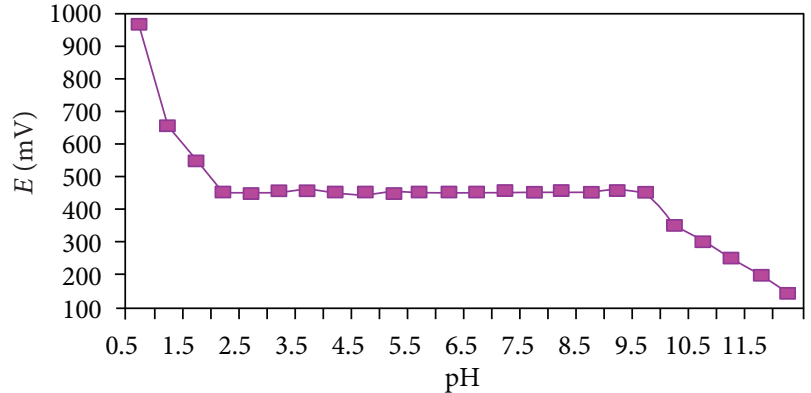

FIgURE 3: The effect of $\mathrm{pH}$ of test solution on the response of the $\mathrm{Mg}^{2+}$ ion selective electrode.

were studied. Also, the optimization of permselectivity of the membrane sensor is known to be highly dependent on the incorporation of additional membrane components [26, 27], therefore, NaTPB has also been added to the membranes with aim to improve the performance of the electrode. As shown in Table 1, the addition of NB plasticizer (sensor no. 3) reduces the slope to $22.0 \mathrm{mV} /$ decade of activity, whereas the performance of the membrane with DPB plasticizer (sensor no. 2) is almost the same as that of membrane without plasticizer (sensor no. 1). The best performance is obtained with TNBP plasticizer with membrane (sensor no. 4) having composition $5: 30: 5: 60$ (MPS : PVC: NaTPB : NTBP) (w/w; $\mathrm{mg}$ ). This sensor exhibits linear response to $\mathrm{Mg}^{2+}$ for wide working concentration range of $1.0 \times 10^{-8}$ to $1.0 \times 10^{-1} \mathrm{M}$ and detection limit $1.7 \times 10^{-9}$ with a near-Nernstian slope of $28.4 \mathrm{mV} /$ decade of activity.

The $\mathrm{pH}$ dependence of the electrode potential was tested over the range 1.0-9.5 for $\mathrm{Mg}^{2+}$ in this concentration $1.0 \times$ $10^{-4}$ shown in Figure 3. The $\mathrm{pH}$ of the solutions was adjusted by the addition of dilute hydrochloric acid or sodium hydroxide. It is clear from Figure 3 that the useful $\mathrm{pH}$ range is $1.0-9.5$, as the potentials remain constant in this range. The sharp change in potentials at higher $\mathrm{pH}$ values may be due to the hydrolysis of $\mathrm{Mg}^{2+}$, while at lower $\mathrm{pH}$ values $\mathrm{H}^{+}$ ions start contributing to the charge transport process of the membrane, thereby, causing interference.

The performance of the sensor (no. 4) was also investigated in partially nonaqueous medium using methanolwater, ethanol-water, and acetone-water mixtures. The membrane worked satisfactorily in nonaqueous medium up to 
TABLE 1: Composition of PVC membrane of (MPS) and performance characteristics of $\mathrm{Mg}^{2+}$-selective sensors based on them.

\begin{tabular}{lcccccccc}
\hline \multirow{2}{*}{ Sensor no. } & \multicolumn{4}{c}{ Component in membranes (w/w) } & \multicolumn{2}{c}{ Working Conc range (M) } & \multirow{2}{*}{ Slope ( \pm mv/decade of activity) } \\
& MPS & PVC & NaTBP & DPB & NB & NTBP & \\
\hline 1 & 5 & 30 & 5 & & & & $1.0 \times 10^{-5}$ to $1.0 \times 10^{-1}$ & 35.5 \\
2 & 5 & 30 & 5 & 60 & & & $1.0 \times 10^{-4}$ to $1.0 \times 10^{-1}$ & 34 \\
3 & 5 & 30 & 5 & & 60 & & $1.0 \times 10^{-5}$ to $1.0 \times 10^{-1}$ & 22 \\
4 & 5 & 30 & 5 & & & 60 & $1.0 \times 10^{-8}$ to $1.0 \times 10^{-1}$ & 28.4 \\
\hline
\end{tabular}

$20 \%(\mathrm{v} / \mathrm{v})$ nonaqueous content as in these mixtures; the working concentration range and slope remained unaffected as shown in Table 2. However, above $20 \%(\mathrm{v} / \mathrm{v})$ nonaqueous content, slope, and working concentration range was reduced, and potentials show drift. It is worth mentioning that the lifetime of the membranes did not alter in nonaqueous solutions.

4.3. Potentiometric Selectivity. The selectivity is the most important characteristics, as it determines the extent of utility of a sensor in real sample measurement. The selectivity coefficient values were determined by fixed interference method (FIM) [28], which was proposed by Gadzekpo and Christian [29]. The selectivity coefficient values $K_{A, B}^{\text {pot }}$ indicate that the electrode is moderately selective to $\mathrm{Mg}^{2+}$ over a number of other cations (Table 3). The potential of a cell comprising an ion-selective electrode and a reference electrode is measured with solutions of constant level of interference, $a_{B}$, and varying activity of the primary ion, $a_{A}$. The potential values obtained are plotted in contrast to the activity of the primary ion. The intersection of the extrapolation of the linear portions of this curve will indicate the value of $a_{A}$ which is to be used to calculate $K_{A, B}^{\mathrm{pot}}$ from the equation:

$$
K_{A, B}^{\text {pot }}=\left(\frac{a_{A}}{a_{B}}\right)^{Z_{A} / Z_{B}},
$$

where both $Z_{A}$ and $Z_{B}$ have the same signs, positive or negative. A value of selectivity coefficient equal to 1.0 indicates that the sensor responds equally to primary as well as interfering ion. However, values smaller then 1.0 indicate that membrane sensor is responding more to primary ion than to interfering ions and in such a case the sensor is said to be selective to primary ion over interfering ion. Further, smaller is the selectivity coefficient, higher is the selectivity order. A perusal of Table 3 shows that selectivity coefficient values for the present sensor are much smaller than 1.0 over a number of mono-, di-, and trivalent cations being studied. Hence, the sensor is sufficiently selective over these ions and can therefore be used to estimate magnesium in presence of these ions by direct potentiometry.

4.4. Response and Lifetime. The average time required for the $\mathrm{Mg}^{2+}$ ion sensor to reach a potential within $\pm 1 \mathrm{mV}$ of final equilibrium value after successive immersion of a series of magnesium(II) ion solutions, each having a 10-fold difference in concentration, was measured. The static response time of

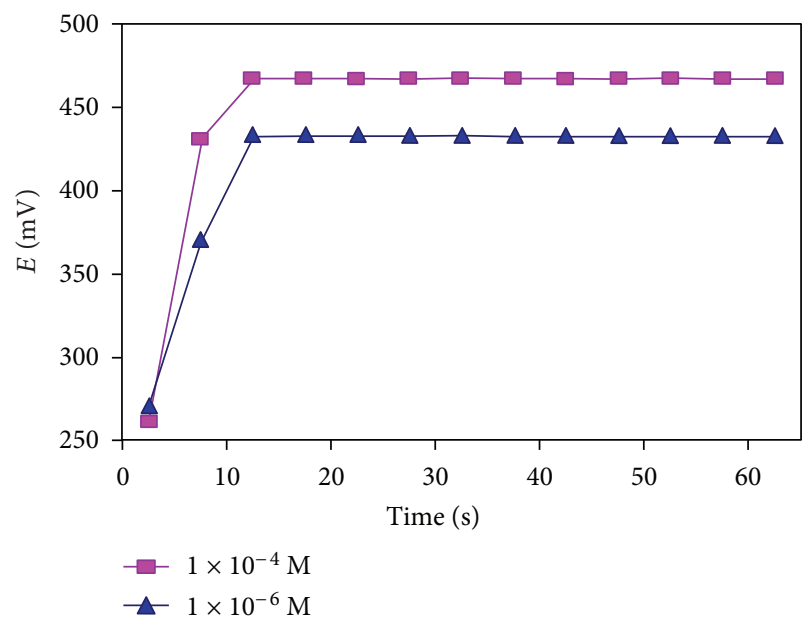

FIGURE 4: The effect of the time on potentiometric response of $\mathrm{Mg}^{2+}$ electrode.

the membrane sensor thus obtained was $<10 \mathrm{~s}$, for concentration $\geq 1.0 \times 10^{-4}$ and $<15$ s for concentration of $\geq 10^{-6}$ (Figure 4). The life time of the proposed $\mathrm{Mg}^{2+}$ sensor was evaluated and tested for 40 weeks, while during this period the sensors were used extensively (one hour per weeks). The obtained results are given in Figure 5. As it obvious, the significant changes in the slope of the $\mathrm{Mg}^{2+}$ sensor were happen after 36 weeks. Thus, the proposed $\mathrm{Mg}^{2+}$ sensor can be used for at least 36 weeks. During this time a slight gradual decrease in the slopes (from 28.4 to $24.3 \mathrm{mV}$ per decade) will be observed. The lifetime of the membrane sensor was about 8 months, during which it could be used without any measurable divergence.

The time of contact and concentration of the equilibrium solution was also optimized so that the sensor generated stable and reproducible potentials at relatively short response time. It was found that an equilibrating solution of $1.0 \times$ $10^{-2} \mathrm{M}$ and contact time of 2 days were appropriate for smooth functioning of the electrode. Membranes were stored in $1.0 \times 10^{-2} \mathrm{M} \mathrm{Mg}\left(\mathrm{NO}_{3}\right)_{2}$ solution when being not used.

4.5. Comparison with Other Reported Electrodes. In Table 4, the response characteristics and the selectivity coefficients of the membrane electrode based on methyl phenyl acetophenonesemicarbazone of some potential interfering ions are compared with the corresponding values previously reported $[18,19,23,30-51]$ for magnesium ion-selective membrane 
TABLE 2: Effect of partially nonaqueous medium on the working of $\mathrm{Mg}^{2+}$ selective sensors (sensor no. 4).

\begin{tabular}{lcc}
\hline Non-aqueous content $\%(\mathrm{v} / \mathrm{v})$ & Working concentration range $(\mathrm{m})$ & Slope $( \pm 0.1 \mathrm{mv} /$ decade of activity) \\
\hline 10 & $1.0 \times 10^{-8}$ to $1.0 \times 10^{-1}$ & 28.4 \\
20 & $1.0 \times 10^{-8}$ to $1.0 \times 10^{-1}$ & 28.4 \\
30 & $1.0 \times 10^{-8}$ to $1.0 \times 10^{-1}$ & 28.2 \\
\hline \multicolumn{1}{c}{ Ethanol } & 28.4 \\
\hline 10 & $1.0 \times 10^{-8}$ to $1.0 \times 10^{-1}$ & 28.4 \\
20 & $1.0 \times 10^{-8}$ to $1.0 \times 10^{-1}$ & 28.2 \\
30 & $1.0 \times 10^{-8}$ to $1.0 \times 10^{-1}$ & \\
\hline 10 & Acetone & \\
20 & $1.0 \times 10^{-8}$ to $1.0 \times 10^{-1}$ & 28.4 \\
30 & $1.0 \times 10^{-8}$ to $1.0 \times 10^{-1}$ & 28.4 \\
\hline
\end{tabular}

TABLE 3: Selectivity coefficient values $K_{A, B}^{\text {pot }}$ for $\mathrm{Mg}^{2+}$-selective sensor by fixed interference method.

\begin{tabular}{lcc}
\hline S. No. & Interfering ion (B) & Selectivity coefficients \\
\hline 1 & $\mathrm{~K}^{+}$ & $6.01 \times 10^{-2}$ \\
2 & $\mathrm{NH}_{4}^{+}$ & $4.03 \times 10^{-2}$ \\
3 & $\mathrm{Cd}^{2+}$ & $6.44 \times 10^{-2}$ \\
4 & $\mathrm{~Pb}^{2+}$ & $8.03 \times 10^{-2}$ \\
5 & $\mathrm{Cu}^{2+}$ & $4.03 \times 10^{-2}$ \\
6 & $\mathrm{Ni}^{2+}$ & $8.11 \times 10^{-2}$ \\
7 & $\mathrm{Zn}^{2+}$ & $5.12 \times 10^{-2}$ \\
8 & $\mathrm{Co}^{2+}$ & $2.01 \times 10^{-2}$ \\
9 & $\mathrm{Ca}^{2+}$ & $1.06 \times 10^{-2}$ \\
10 & $\mathrm{Sr}^{2+}$ & $3.01 \times 10^{-2}$ \\
11 & $\mathrm{Cr}^{3+}$ & $1.01 \times 10^{-2}$ \\
12 & $\mathrm{Al}^{3+}$ & $6.01 \times 10^{-2}$ \\
\hline
\end{tabular}

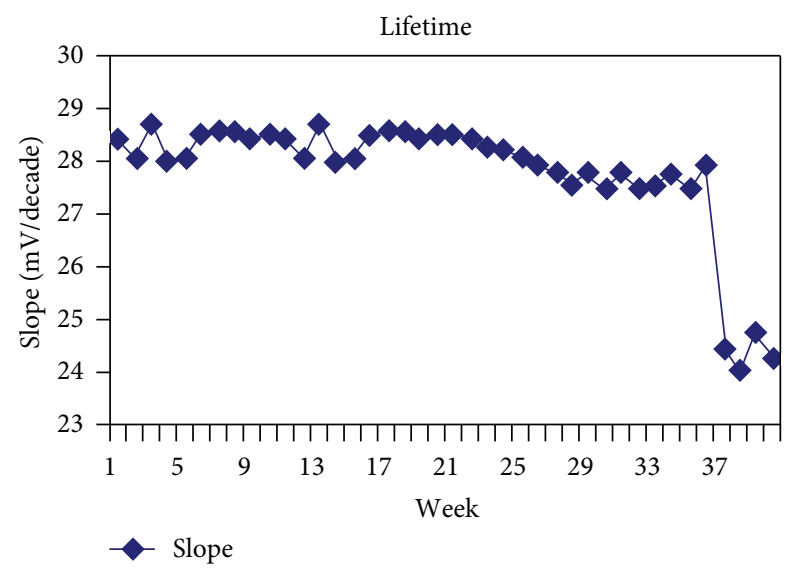

FIGURE 5: Lifetime of the proposed sensor.

electrodes based on a variety of different ionophores. As can be seen, the linear range and the response time of the proposed electrode are superior to those reported for magnesium ion-selective electrodes, and its selectivity behavior is among.

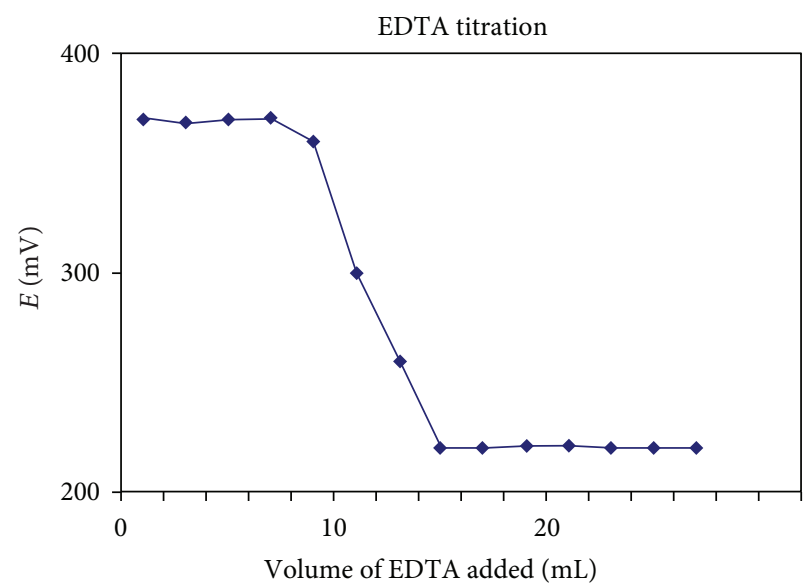

Figure 6: Potentiometric titration curve of $\mathrm{Mg}^{2+}$ ion $\left(1.0 \times 10^{-3} \mathrm{M}\right.$, $20.0 \mathrm{~mL})$ with EDTA $\left(1.25 \times 10^{-3} \mathrm{M}\right)$, using the proposed sensor as an indicator electrode.

\section{Analytical Applications}

5.1. Potentiometric Titration. The membrane sensor could be successfully used in the potentiometric titration of $\mathrm{Mg}^{2+}$ with EDTA. A $20 \mathrm{~mL}\left(1.0 \times 10^{-3} \mathrm{M}\right)$ solution of $\mathrm{Mg}^{2+}$ was titrated with $1.25 \times 10^{-3} \mathrm{M}$ EDTA (Figure 6). On the addition of EDTA, the concentration of $\mathrm{Mg}^{2+}$ ions decreases, causing a decrease in potential in line. However, the break point is sharp and corresponds to the stoichiometry of $\mathrm{Mg}$ (II)-EDTA complex. After the end-point, potentials are almost constant because now the sensor is not responding to small changes in $\mathrm{Mg}^{2+}$ concentration. Thus the electrode assembly can be used for magnesium ions determination by potentiometric titration.

\section{Conclusion}

The plasticized PVC-based membrane incorporating methyl phenyl semicarbazone as an ionophore, TNBP as solvent mediator, and NaTBP as anion excluder in a PVC 
TABLE 4: Comparison with other reported electrodes.

\begin{tabular}{|c|c|c|c|c|c|c|c|}
\hline S. No. & Detection Limit & $\mathrm{pH}$ range & Slope & Liner range & Response (Sec) & life time & Reference \\
\hline 1 & $1.7 \times 10^{-9}$ & $1.0-9.5$ & 28.4 & $1.0 \times 10^{-8}$ to $1.0 \times 10^{-1}$ & 10 & 8 months & This work \\
\hline 2 & - & $2.2-9.8$ & 31.1 & $1.0 \times 10^{-5}$ to $1.0 \times 10^{-5}$ & 15.5 & 4 months & [18] \\
\hline 3 & - & - & - & - & - & - & {$[30]$} \\
\hline 4 & $1 \times 10^{-5}$ & - & 28.6 & - & - & 1 weak & {$[19]$} \\
\hline 5 & - & - & 30 & 0.1 to $3.2 \times 10^{-5}$ & - & 1 month & [23] \\
\hline 6 & - & $3.5-7.8$ & 29.2 & $9.4 \times 10^{-6}$ to $1.0 \times 10^{-1}$ & 13 & - & {$[31]$} \\
\hline 7 & - & $2.5-6.5$ & 29 & $1.9 \times 10^{-6}$ to $1.0 \times 10^{-1}$ & 15 & - & {$[32]$} \\
\hline
\end{tabular}

matrix could be use to determine $\mathrm{Mg}^{2+}$ in the concentration range $1.0 \times 10^{-8}$ to $1.0 \times 10^{-1} \mathrm{M}$. The membrane was prepared using the fixed ratio of $5: 30: 5: 60(\mathrm{w} / \mathrm{w})$ (ionophore: PVC: NaTBP: NTBP). The detection limit was found to be $1.7 \times 10^{-9}$ with a slope of $28.4 \mathrm{mV} /$ decade of activity. The sensor works in a wide $\mathrm{pH}$ range 1.0 to 9.5 with a response time of $10 \mathrm{~s}$. The selectivity of the electrode towards $\mathrm{Mg}^{2+}$ is quite well understood over the other cation. The lifetime of the assembly is 8 months in both aqueous and nonaqueous medium. In addition, the membrane sensor can also be used as an indicator electrode in potentiometric titration involving magnesium(II) ions against EDTA.

\section{Acknowledgment}

The financial support provided by the Defense Research and Development Organization (DRDO), New Delhi, India, is greatly acknowledged.

\section{References}

[1] P. Paker, McGraw-Hill Concise Encyclopaedia of Science and Technology, McGraw-Hill, New York, NY, USA, 1994.

[2] S. F. D'Souza, "Microbial biosensors," Biosensors and Bioelectronics, vol. 16, no. 6, pp. 337-353, 2001.

[3] M. Shamsipur, A. Soleymanpour, M. Akhond, H. Sharghi, and A. R. Massah, "Uranyl-selective PVC membrane electrodes based on some recently synthesized benzo-substituted macrocyclic diamides," Talanta, vol. 58, no. 2, pp. 237-246, 2002.

[4] Z. R. Zhang and R. Q. Yu, "The synthesis and membrane transport characteristics of macrocyclic polyether ligands composed of 1,10-phenanthroline as carriers for primary amine species," Talanta, vol. 41, no. 2, pp. 327-333, 1994.

[5] A. K. Singh, P. Saxena, S. Mehtab, and B. Gupta, "Strontium(II)selective electrode based on a macrocyclic tetraamide," Talanta, vol. 69, no. 2, pp. 521-526, 2006.

[6] A. K. Singh, P. Saxena, and A. Panwar, "Manganese(II)-selective PVC membrane electrode based on a pentaazamacrocyclic manganese complex," Sensors and Actuators B, vol. 110, no. 2, pp. 377-381, 2005.

[7] M. R. Ganjali, T. Razavi, R. Dinarvand, S. Riahi, and P. Norouzi, "New diltiazem potentiometric membrane sensor stands on theoretical calculations as a useful device for diltiazem hydrochloride analysis in pharmaceutical formulation and urine," International Journal of Electrochemical Science, vol. 3, pp. 1543-1558, 2008.
[8] M. R Ganjali, Z. Memari, F. Faridbod, and P. Norouzi, "Samarium microsensor: an asymetric potentiometric membrane sensor," International Journal of Electrochemical Science, vol. 3, pp. 1169-1179, 2008.

[9] S. S. Beheshti and M. K. Amini, "A simple and selective flowinjection potentiometric method for determination of iodide based on a coated glassy carbon electrode sensor," International Journal of Electrochemical Science, vol. 2, pp. 778-787, 2007.

[10] H. Zhang, Z. Zhang, J. Li, and Sh. Cai, "Effects of $\mathrm{Mg}^{2+}$ on supported bilayer lipid membrane on a glassy carbon electrode during membrane formation," International Journal of Electrochemical Science, vol. 2, pp. 788-796, 2007.

[11] J. Reglinski, S. Morris, and D. E. Stevenson, "Supporting conformational change at metal centres. Part 2: four and five coordinate geometry," Polyhedron, vol. 21, no. 21, pp. 2175-2182, 2002.

[12] S. Yamada, "Advancement in stereochemical aspects of Schiff base metal complexes," Coordination Chemistry Reviews, vol. 190, pp. 537-555, 1999.

[13] S. Memon and M. Yilmaz, "An excellent approach towards the designing of a Schiff-base type oligocalix[4]arene, selective for the toxic metal ions," Journal of Macromolecular Science, vol. 39 A, no. 1-2, pp. 63-73, 2002.

[14] Z. Cimerman, N. Galic, and B. Bosner, "The Schiff bases of salicylaldehyde and aminopyridines as highly sensitive analytical reagents," Analytica Chimica Acta, vol. 343, no. 1-2, pp. 145-153, 1997.

[15] J. Šima, P. Fodran, J. Hledík, A. Kotočová, and D. Valigura, "Central atom exchange reactions in complexes with tetradentate thiominato schiff base ligand," Inorganica Chimica Acta, vol. 81, pp. 143-146, 1984.

[16] P. G. Cozzi, "Metal-Salen Schiff base complexes in catalysis: practical aspects," Chemical Society Reviews, vol. 33, no. 7, pp. 410-421, 2004.

[17] M. Maj-Zurawska, M. Rouilly, W. E. Morf, and W. Simon, "Determination of magnesium and calcium in water with ionselective electrodes," Analytica Chimica Acta, vol. 218, pp. 47-59, 1989.

[18] V. K. Gupta, S. Chandra, and R. Mangla, "Magnesium-selective electrodes," Sensors and Actuators B, vol. 86, no. 2-3, pp. 235-241, 2002.

[19] X. Zhang, A. Fakler, and U. E. Spichiger, "Development of magnesium-ion-selective microelectrodes based on a new neutral carrier ETHT 5504," Electroanalysis, vol. 10, no. 17, pp. 1174-1181, 1998.

[20] W. Zhang, L. Jenny, and U. E. Spichiger, "A comparison of neutral $\mathrm{Mg}^{2+}$-selective ionophores in solvent polymeric membranes: complex stoichiometry and lipophilicity," Analytical Sciences, vol. 16, no. 1, pp. 11-18, 2000. 
[21] M. Müller, M. Rouilly, B. Rusterholz, M. Maj-Zurawska, Z. $\mathrm{Hu}$, and W. Simon, "Magnesium selective electrodes for blood serum studies and water hardness measurement," Mikrochimica Acta, vol. 96, no. 1-6, pp. 283-290, 1988.

[22] J. O’Donnell, B. Rusterholz, B. Aebersold, D. Rüegg, W. Simon, and E. Pretsch, "Influence of structural changes on the ion selectivities of magnesium ionophores based on malonic acid diamides," Mikrochimica Acta, vol. 113, no. 1-2, pp. 45-52, 1994.

[23] M. Saleh, "Neutral carrier-based magnesium-selective electrode," Journal of Electroanalytical Chemistry, vol. 373, no. 1-2, pp. 89-95, 1994.

[24] S. Brian Furniss Antony, J. Hannatord-Petter, W. G. Smith Austin, and R. Tachell, Book of Practical Organic Chemistry Vogel's, 2004.

[25] A. Craggs, L. Keil, G. J. Moody, and J. D. R. Thomas, "An evaluation of solvent mediators for ion-selective electrode membranes based on calcium bis(dialkylphosphate) sensors trapped in poly(vinyl chloride) matrices," Talanta, vol. 22, no. 10-11, pp. 907-910, 1975.

[26] E. Bakker, P. Bühlmann, and E. Pretsch, "Carrier-based ionselective electrodes and bulk optodes. 1. General characteristics," Chemical Reviews, vol. 97, no. 8, pp. 3083-3132, 1997.

[27] S. Chandra, A. Rawat, and A. Sarkar, "Thiocyanate-selective PVC membrane electrode based on copper and nickel complexes of para-tolualdehydesemicarbazone as carrier," Analytical Letters, vol. 41, no. 17, pp. 3058-3073, 2008.

[28] F. J. S. De Viteri and D. Diamond, "Determination and application of ion-selective electrode model parameters using flow injection and simplex optimization," The Analyst, vol. 119, no. 5, pp. 749-758, 1994.

[29] V. P. Y. Gadzekpo and G. D. Christian, "Determination of selectivity coefficients of ion-selective electrodes by a matchedpotential method," Analytica Chimica Acta, vol. 164, pp. 279-282, 1984.

[30] K. Suzuki, K. Watanabe, Y. Matsumoto et al., "Design and synthesis of calcium and magnesium ionophores based on doublearmed diazacrown ether compounds and their application to an ion-sensing component for an ion-selective electrode," Analytical Chemistry, vol. 67, no. 2, pp. 324-334, 1995.

[31] V. K. Gupta, R. Prasad, and A. Kumar, "Magnesium-tetrazaporphyrin incorporated PVC matrix as a new material for fabrication of $\mathrm{Mg}^{2+}$ selective potentiometric sensor," Talanta, vol. 63, no. 4, pp. 1027-1033, 2004.

[32] S. Baniwal, S. Chandra, A. Panwar, and A. K. Singh, "Poly(vinyl chloride)-based macrocyclic membrane sensors for magnesium," Talanta, vol. 50, no. 3, pp. 499-508, 1999.

[33] V. K. Gupta, "Potentiometric sensors for heavy metals-an overview," Chimia, vol. 59, no. 5, pp. 209-217, 2005.

[34] V. K. Gupta, M. R. Ganjali, P. Norouzi, H. Khani, A. Nayak, and S. Agarwal, "Electrochemical analysis of some toxic metals by ion-selective electrodes," Critical Reviews in Analytical Chemistry, vol. 41, no. 4, pp. 282-313, 2011.

[35] V. K. Gupta, B. Sethi, N. Upadhyay, S. Kumar, R. Singh, and L. P. Singh, "Iron (III) selective electrode based on S-methyl N(methylcarbamoyloxy) thioacetimidate as a sensing material," International Journal of Electrochemical Science, vol. 6, no. 3, pp. 650-663, 2011.

[36] V. K. Gupta, A. K. Jain, M. K. Pal, S. Agarwal, and A. K. Bharti, "A comparative study on PVC based sensors in determination of molybdenum," Analytical Methods, vol. 3, no. 2, pp. 334-342, 2011.
[37] V. K. Gupta, M. Al Khayat, A. K. Singh, and M. K. Pal, "Nano level detection of Cd(II) using poly(vinyl chloride) based membranes of Schiff bases," Analytica Chimica Acta, vol. 634, no. 1, pp. 36-43, 2009.

[38] V. K. Gupta, A. K. Singh, M. Al Khayat, and B. Gupta, "Neutral carriers based polymeric membrane electrodes for selective determination of mercury (II)," Analytica Chimica Acta, vol. 590, no. 1, pp. 81-90, 2007.

[39] A. K. Singh, V. K. Gupta, and B. Gupta, "Chromium(III) selective membrane sensors based on Schiff bases as chelating ionophores," Analytica Chimica Acta, vol. 585, no. 1, pp. 171-178, 2007.

[40] A. K. Jain, V. K. Gupta, L. P. Singh, and J. R. Raisoni, "A comparative study of $\mathrm{Pb}^{2+}$ selective sensors based on derivatized tetrapyrazole and calix[4]arene receptors," Electrochimica Acta, vol. 51, no. 12, pp. 2547-2553, 2006.

[41] V. K. Gupta and S. Agarwal, "PVC based 5,10,15,20-tetrakis (4methoxyphenyl) porphyrinatocobalt(II) membrane potentiometric sensor for arsenite," Talanta, vol. 65, no. 3, pp. 730-734, 2005.

[42] V. K. Gupta, S. Chandra, and R. Mangla, "Dicyclohexano18-crown-6 as active material in PVC matrix membrane for the fabrication of cadmium selective potentiometric sensor," Electrochimica Acta, vol. 47, no. 10, pp. 1579-1586, 2002.

[43] V. K. Gupta, R. Mangla, and S. Agarwal, "Pb(II) selective potentiometric sensor based on 4-tert-butylcalix[4]arene in PVC matrix," Electroanalysis, vol. 14, no. 15-16, pp. 1127-1132, 2002.

[44] P. K. Tomar, S. Chandra, A. Malik, A. Kumar, and A. Kumar, "Chromium (III) ion selective PVC membrane electrode based on a schiff base ligand, 3-aminoacetophenone thiosemicarbazone," Analytical \& Bioanalytical Electrochemistry, vol. 3, pp. 119-133, 2011.

[45] V. K. Gupta and P. Kumar, "Cadmium(II)-selective sensors based on dibenzo-24-crown-8 in PVC matrix," Analytica Chimica Acta, vol. 389, no. 1-3, pp. 205-212, 1999.

[46] V. K. Gupta, R. Mangla, U. Khurana, and P. Kumar, "Determination of uranyl ions using poly(vinyl chloride) based 4-tertbutylcalix[6]arene membrane sensor," Electroanalysis, vol. 11, no. 8, pp. 573-576, 1999.

[47] S. K. Srivastava, V. K. Gupta, and S. Jain, "PVC-based 2,2,2cryptand sensor for zinc ions," Analytical Chemistry, vol. 68, no. 7, pp. 1272-1275, 1996.

[48] S. K. Srivastava, V. K. Gupta, and S. Jain, "Determination of lead using a poly(vinyl chloride)-based crown ether membrane," The Analyst, vol. 120, no. 2, pp. 495-498, 1995.

[49] S. K. Srivastava, V. K. Gupta, M. K. Dwivedi, and S. Jain, "Caesium PVC-crown (dibenzo-24-crown-8) based membrane sensor," Analytical Proceedings including Analytical Communications, vol. 32, no. 1, pp. 21-23, 1995.

[50] A. K. Jain, V. K. Gupta, B. B. Sahoo, and L. P. Singh, "Copper(II)-selective electrodes based on macrocyclic compounds," Analytical Proceedings, vol. 32, no. 3, pp. 99-101, 1995.

[51] A. K. Jain, V. K. Gupta, and L. P. Singh, "Neutral carrier and organic resin based membranes as sensors for uranyl ions," Analytical Proceedings, vol. 32, no. 7, pp. 263-266, 1995. 

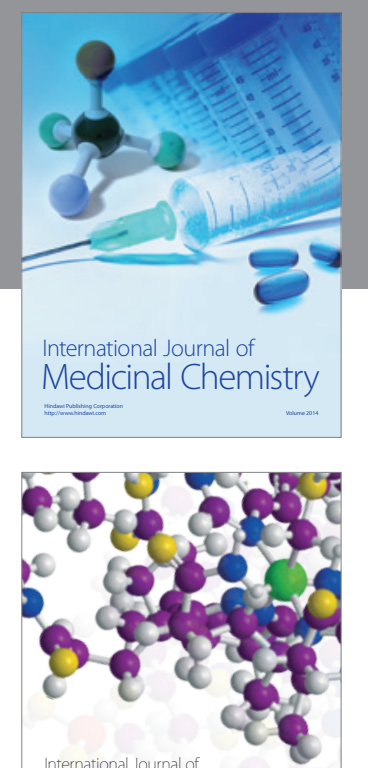

\section{Carbohydrate} Chemistry

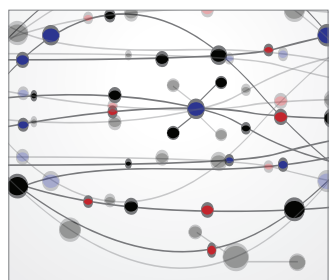

The Scientific World Journal
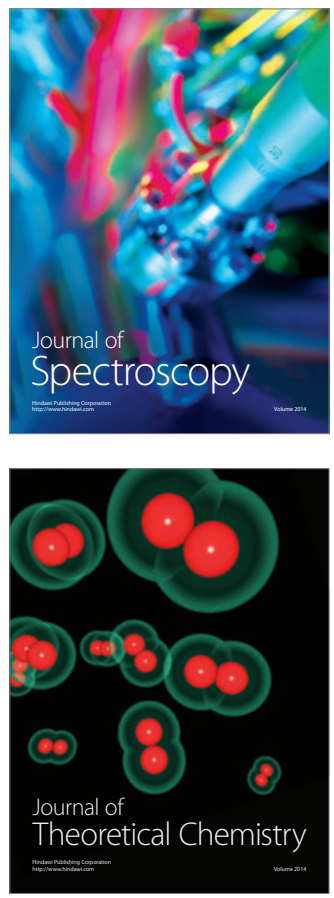
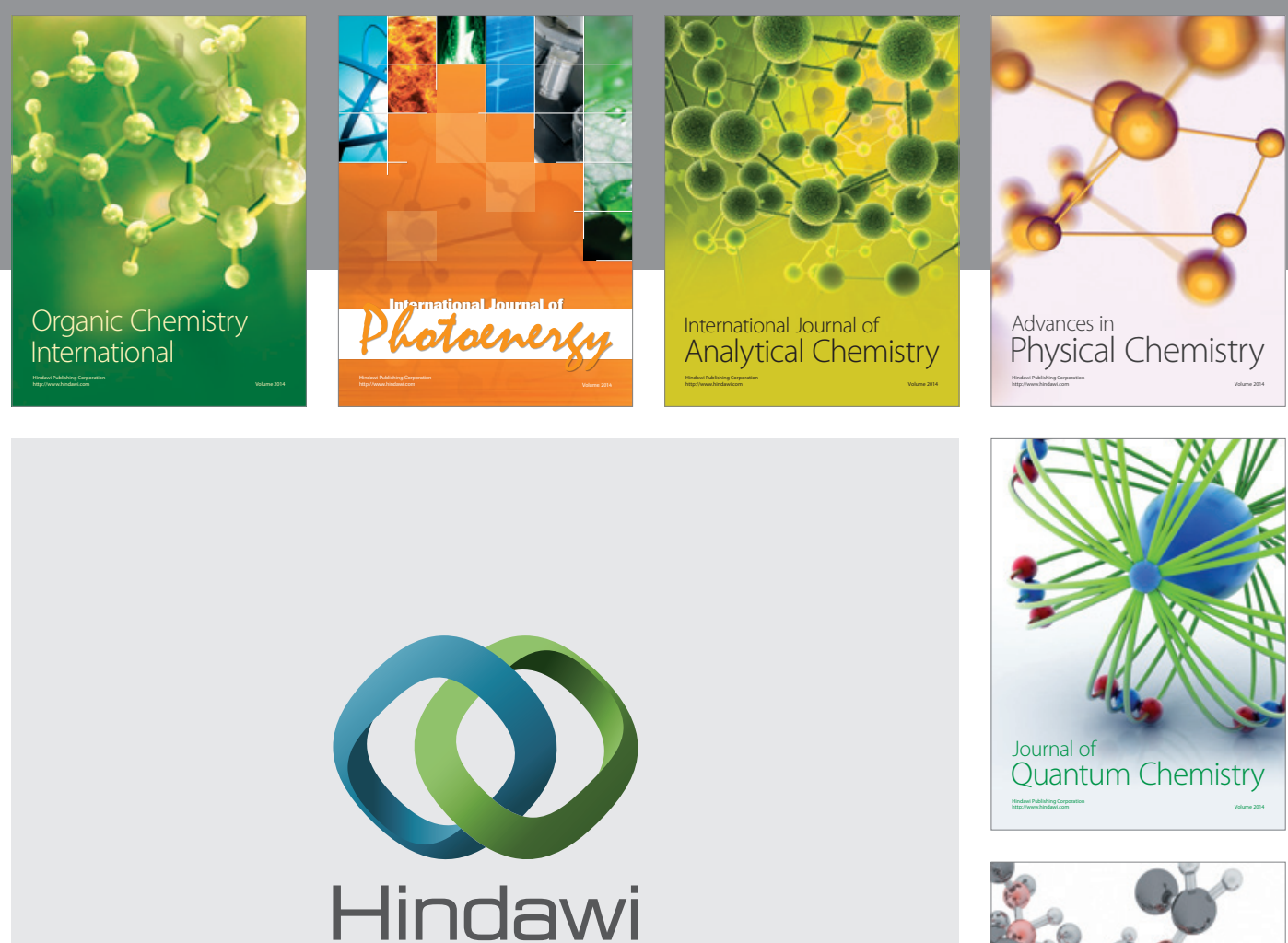

Submit your manuscripts at

http://www.hindawi.com

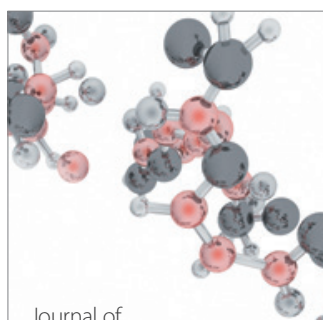

Analytical Methods

in Chemistry

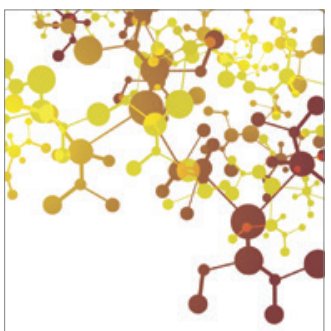

Journal of

Applied Chemistry

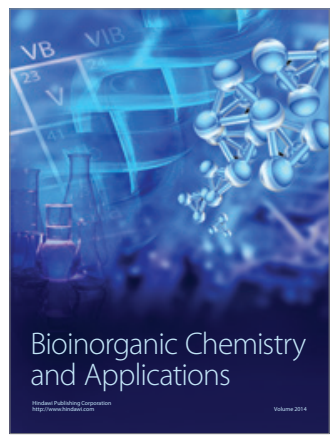

Inorganic Chemistry
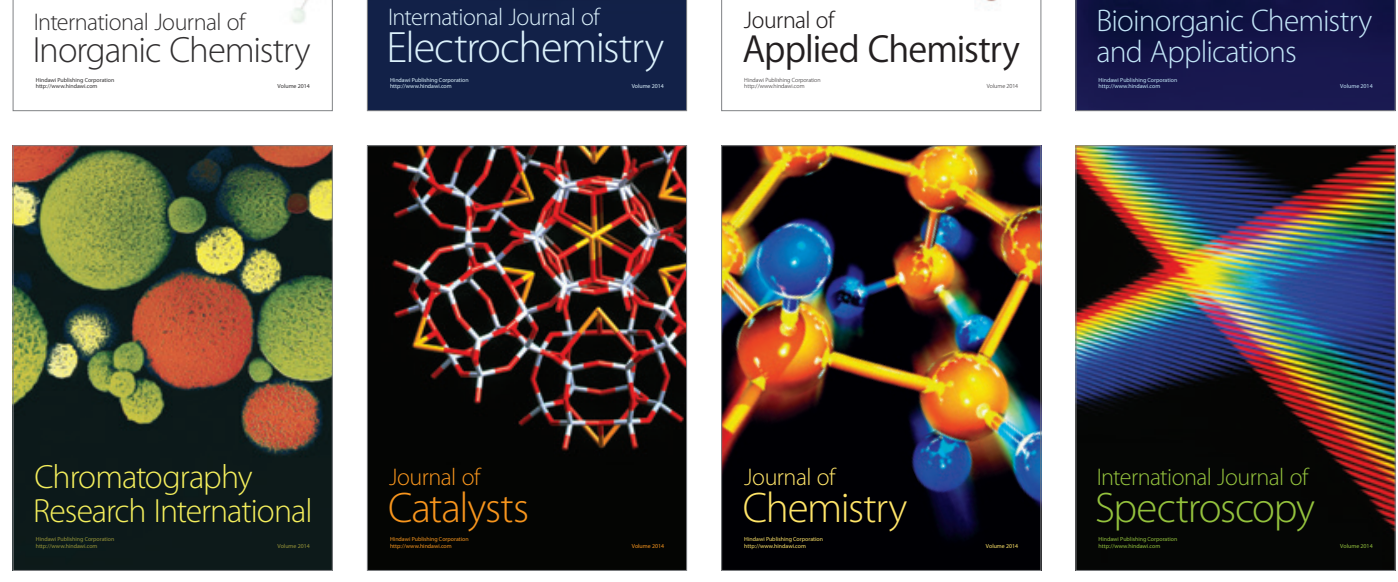